\title{
Teicoplanin-based antimicrobial therapy in Staphylococcus aureus bone and joint infection: tolerance, efficacy and experience with subcutaneous administration
}

Olivier Peeters ${ }^{1,2,3}$, Tristan Ferry ${ }^{1,2,4}$, Florence Ader ${ }^{1,2,4}$, André Boibieux ${ }^{1,2}$, Evelyne Braun ${ }^{1,2}$, Anissa Bouaziz ${ }^{5}$ Judith Karsenty ${ }^{6}$, Emmanuel Forestier ${ }^{7}$, Frédéric Laurent ${ }^{1,4,8}$, Sébastien Lustig ${ }^{1,4,9}$, Christian Chidiac ${ }^{1,2,4}$, Florent Valour ${ }^{1,2,4^{*}}$ (D) and on behalf of the Lyon BJ study group

\begin{abstract}
Background: Staphylococci represent the first etiologic agents of bone and joint infection (BJI), leading glycopeptides use, especially in case of methicillin-resistance or betalactam intolerance. Teicoplanin may represent an alternative to vancomycin because of its acceptable bone penetration and possible subcutaneous administration.

Methods: Adults receiving teicoplanin for S. aureus BJ were included in a retrospective cohort study investigating intravenous or subcutaneous teicoplanin safety and pharmacokinetics.

Results: Sixty-five S. aureus BJls (orthopedic device-related infections, $69 \%$; methicillin-resistance, $17 \%$ ) were treated by teicoplanin at the initial dose of $5.7 \mathrm{mg} / \mathrm{kg} /$ day (IQR, 4.7-6.5) after a loading dose of 5 injections $12 \mathrm{~h}$ apart. The first trough teicoplanin level $\left(C_{\mathrm{min}}\right)$ reached the therapeutic target $(15 \mathrm{mg} / \mathrm{L})$ in $26 \%$ of patients, only. An overdose $\left(C_{\min }>25 \mathrm{mg} / \mathrm{L}\right)$ was observed in $16 \%$ patients, $50 \%$ of which had chronic renal failure $(p=0.049)$. Seven adverse events occurred in 6 patients (10\%); no predictive factor could be highlighted. After a 91-week follow-up (IQR, 51-183), 27 treatment failures were observed (42\%), associated with diabetes (OR, 5.1; $p=0.057)$, systemic inflammatory disease $(\mathrm{OR}, 5.6 ; p=0.043)$, and abscess $\left(\mathrm{OR}, 4.1 ; p<10^{-3}\right)$. A normal CRP-value at 1 month was protective $(\mathrm{OR}, 0.2 ; p=0.029)$. Subcutaneous administration $(n=14)$ showed no difference in pharmacokinetics and tolerance compared to the intravenous route.
\end{abstract}

Conclusions: Teicoplanin constitutes a well-tolerated therapeutic alternative in S. aureus BJI, with a possible subcutaneous administration in outpatients. The loading dose might be increase to 9-12 mg/kg to quickly reach the therapeutic target, but tolerance of such higher doses remains to be evaluated, especially if using the subcutaneous route.

Keywords: Bone and joint infection, Staphylococcus aureus, Teicoplanin, Subcutanous administration

\footnotetext{
* Correspondence: florent.valour@chu-lyon.fr

${ }^{1}$ Regional Referral Center for Bone and Joint Infection, Hospices Civils de Lyon, Lyon, France

2Infectious Disease Department, Hospices Civils de Lyon, Groupement Hospitalier Nord, 103 Grande Rue de la Croix-Rousse, 69004 Lyon, France Full list of author information is available at the end of the article
} 


\section{Background}

Staphylococci are the first etiologic agents of bone and joint infection (BJI). Methicillin-susceptible Staphylococcus aureus (MSSA) is predominant and antistaphylococcal penicillins such as nafcillin, oxacillin and cloxacillin are the backbone molecules for the initial antimicrobial therapy $[1,2]$. Nevertheless, glycopeptide alternative, including vancomycin or teicoplanin, remains frequently used for several reasons: i) although hospital diffusion of methicillin-resistant clones of S. aureus (MRSA) is currently controlled in France, MRSA still accounts for $20 \%$ of $S$. aureus isolates involved in BJI [3]; ii) half of staphylococcal BJI are caused by coagulase negative staphylococci (CNS), among which methicillin resistance has continuously increased in the past years to presently reach $50 \%$ of isolates [3]; and iii) antistaphylococcal penicillins are the first cause of antimicrobial-related adverse events during long-term treatment of staphylococcal BJI [4], in case of which glycopeptides are the first alternative. If vancomycin is largely prescribed in this context, teicoplanin could theoretically represent an acceptable alternative in BJI as studies have shown a comparable efficacy compared to vancomycin in various other conditions [5] and an improved safety profile with fewer renal toxicity [6], as well as the possibility of daily subcutaneous injection, of particular interest for outpatient parenteral antimicrobial therapy (OPAT). In addition, various studies have shown that teicoplanin pharmacodynamic profile was superior compared to vancomycin regarding bone diffusion $[7,8]$. Few studies have investigated the use of teicoplanin in BJI, particularly through subcutaneous administration. The present study assesses the efficacy and tolerance of teicoplanin in $S$. aureus BJI, especially focusing on subcutaneous use.

\section{Methods}

Inclusion criteria and data collection

A retrospective single-center observational cohort study (2001 to 2011) was conducted including all consecutive patients managed at our institution receiving teicoplanin as part of $S$. aureus BJI treatment. Patients diagnosed with staphylococcal BJI were identified by cross-referencing the prospective maintained databases of the regional referral center for BJI and the bacteriology laboratory, which list exhaustively all strains isolated from osteoarticular samples since 2001. Patients with diabetic foot- and decubitus ulcer-related BJI were excluded, as they require a specific management [9]. If patients presented more than one osteoarticular infected site, they were considered as independent events for cohort description and outcome analysis, but pooled for tolerance and pharmacologic evaluation. For each patient, data were collected from medical records, nursing charts and biological software in an anonymous standardized case report form. All available trough teicoplanin plasmatic levels $\left(C_{\text {min }}\right)$ in the first 14 days of treatment were recorded.

\section{Definitions}

BJI diagnosis was based upon the existence of clinical and biological evidences of infection, and at least one reliable bacteriological sample positive for $S$. aureus (i.e., percutaneous joint fluid aspiration, surgical sample, and/or blood culture). BJI were classified according to: i) the existence of orthopedic implant (i.e. joint prosthesis, peripheral or vertebral osteosynthesis); and ii) progression of infection, differentiating acute ( $\leq 3$ weeks) versus chronic (>3 weeks) infection, calculated from the presumed date of inoculation (i.e., date of device implantation for postoperative orthopaedic device-related infection (ODI), or date of symptom onset for native BJI) up to diagnosis.

The modified Charlson's comorbidity index was calculated as previously described [10]. Immunosuppression was defined as: i) corticosteroid therapy $>10 \mathrm{mg}$ of prednisone per day or equivalent for at least 3 months; ii) immunosuppressive drug(s) during the two last months before BJI onset; or iii) chemotherapy for hematological malignancy or solid tumor.

A $\mathrm{C}_{\min }>15 \mathrm{mg} / \mathrm{L}$ was taken as an acceptable therapeutic target. Patients with a $\mathrm{C}_{\min }>25 \mathrm{mg} / \mathrm{L}$ were considered as overexposure.

Teicoplanin-related adverse events (AE) occurring during follow-up were notified and classified according to the Common Terminology Criteria for Adverse Events (CTCAE, National Cancer Institute, 2003). Teicoplanin accountability in the $\mathrm{AE}$ occurrence was left to the clinician appreciation, with the help of a pharmacovigilance specialist in doubtful cases.

Treatment failure was defined as persisting infection under appropriate antimicrobial therapy, relapse after the interruption of antimicrobial therapy, necessity of surgical revision on the account of persisting septic focus $\geq 5$ days after the first intervention, superinfections, and/or fatal outcome if BJI-related.

\section{Teicoplanin administration}

For intravenous (IV) administration, each dose was diluted in $100 \mathrm{~mL}$ of isotonic saline solution and administrated over a 30-min period. For subcutaneous (SC) injections, each dose was diluted in $50 \mathrm{~mL}$ of isotonic saline solution and delivered by a nurse during a 30- to 60-min gravity infusion using a butterfly disposable needle.

\section{Statistical analysis}

Descriptive statistics were used to estimate the frequencies of the study variables, described as percentages (\%) for dichotomous variables, and medians (interquartile 
range (IQR)) for continuous variables. For the percentage calculation of each variable, the number of missing values was excluded from the denominator. Nonparametric statistical methods were used to compare the study groups (Chi-squared test, Fisher exact test and Mann-Whitney $U$ test), as appropriate. Determinants of teicoplanin-related $\mathrm{AE}$ and treatment failure were assessed using binary logistic regression, including the clinically relevant variables in each model, and expressed by their Odd ratio (OR) and $95 \%$ confidence intervals $(95 \% \mathrm{CI})$. Clinically pertinent variables with a $p$-value $<0.15$ in the univariate analysis were included in the final multivariate models. A value of $p<0.05$ was considered as significant. All analyses were performed using SPSS software version 19.0 (SPSS, Chicago, IL).

\section{Results}

\section{Population characteristics}

Sixty patients were included ( 34 male, $56.7 \%$; median age, 62 years (interquartile range (IQR), 48-75), among who two and one presented three and two concomitant infected osteoarticular site, respectively. Consequently, a total of 65 episodes of BJI were analyzed, including 20 (30.8\%) native and 45 (69.2\%) orthopedic device-related (ODI) infections, and 23 (35.4\%) chronic infections. A MRSA was implicated in $11(16.9 \%)$ cases and 17 (26.2\%) infections were plurimicrobial. All staphylococcal isolates were susceptible to teicoplanin. A surgical procedure was performed in $50(76.9 \%)$ cases, predominantly in ODI (93.3\%). All patients were initially treated by a combination antimicrobial therapy. Median total duration of treatment was 26.8 (IQR, 17.7-42.8) weeks. Patients' characteristics are described in Table 1.

\section{Teicoplanin prescription modalities}

Teicoplanin was used at the median dose of 5.7 (IQR, 4.7-6.5) $\mathrm{mg} / \mathrm{kg}$ administrated in a single daily injection, after a loading dose $(n=55,85.9 \%)$ of 5 (IQR, $5-5)$ injections of 5.7 (IQR, 4.7-6.5) mg/kg/12 h. Median total duration of teicoplanin therapy was 6.0 (IQR, 2.7-9.9) weeks. Teicoplanin was mostly administrated via IV route $(n=51,78.5 \%)$, but $14(21.5 \%)$ cases were treated by $\mathrm{SC}$ route with no difference regarding prescription modalities (median dose, loading dose, duration) compared with IV-treated patients (Table 1). The median number of SC injections per patient was 39.5 (IQR, 24.0-86.5), with a maximum of $600 \mathrm{mg}$ of teicoplanin per injection. Seven switches in administration route were observed, all in patients initially receiving IV treatment. The main teicoplanin companion drugs were fluoroquinolones (44.6\%), rifampicin (24.6\%) and pristinamycin (16.9 \%).

\section{Pharmacological data}

During the first 14 days of treatment, at least one $C_{\text {min }}$ value was available in 59 patients, in whom a median of 2 (IQR, 2-3) dosages was performed during this period. An early $\mathrm{C}_{\min }$ (on day 3,4 or 5 ) was available in 44 patients and was under the therapeutic target of $15 \mathrm{mg} / \mathrm{L}$ in $73.5 \%$ of them, with a median value of $11.7 \mathrm{mg} / \mathrm{L}$. A $\mathrm{C}_{\mathrm{min}}$ $>15 \mathrm{mg} / \mathrm{L}$ was finally obtained in only 39 (66.1\%) patients within the first 2 weeks of treatment, in a median delay of 9 (IQR, 6-13) days, without difference between the IV and SC routes of administration (Fig. 1). No difference was observed between patients who reached or not the therapeutic target of $15 \mathrm{mg} / \mathrm{L}$ (Additional file 1: Table S1).

During the first 2 weeks of treatment, an overexposure was observed in 8 patients who had a significantly older age (76.0 year-old, $p=0.007$ ) and modified Charlson comorbidity index $(7.5, p=0.001)$ than those with no overexposure (Additional file 1: Table S1). Their baseline renal function was more frequently impaired $(50.0 \%, p=0.049)$.

\section{Tolerance}

Seven adverse events occurred in $6(10.0 \%)$ of the 60 included patients, consisting in 5 cutaneous rashes, 1 episode of headache, and one pancytopenia (Table 2). IV and SC routes were implicated in four and one cases, respectively $(p=0.617)$. No difference was shown between patients presenting or not a teicoplanin-related $\mathrm{AE}$, and no predictive factor could be highlighted and especially chronic renal failure, daily dose and early overdose (Additional file 2: Table S2). Of note, no severe $\mathrm{AE}$ was reported at the injection site in the $\mathrm{SC}$ group. The occurrence of an adverse event did not significantly impact outcome.

\section{Outcome}

In a median follow-up of 91.1 (IQR, 50.6-182.6) weeks, 27 treatment failure were observed, including persisting infections $(n=18 ; 66.7 \%)$, relapses $(n=6 ; 22.2 \%)$ and/ or superinfections $(n=13 ; 48.1 \%)$, leading to iterative surgical procedure(s) in 23 (35.4\%) cases including two limb amputations. One sepsis-related death was observed.

In univariate analysis, pertinent variables associated with therapeutic failure with a $p$-value $<0.15$ were inflammatory systemic disease (OR, 5.600; 95 \% CI, 1.056-29.683), diabetes mellitus (OR, 5.143; $95 \% \mathrm{CI}, 0.951-27.826)$, and abscess (OR, 4.073; 95 \% CI, 1.420-11.684). The return to baseline $\mathrm{C}$-reactive protein value at 1 month was associated with a lower risk of treatment failure (OR, 0.214; 95 $\% \mathrm{CI}, 0.051-0.852)$. In multivariate analysis, in situ abscess was independently associated with treatment failure (OR, 3.641; 95 \% CI, 1.110-11.944) (Additional file 3: Table S3). Of note, teicoplanin administration route did not influence the outcome. 
Table 1 Description of the 65 included episodes of BJl and comparison between the intravenous and subcutaneous routes of administration

\begin{tabular}{|c|c|c|c|c|}
\hline & $\begin{array}{l}\text { Total population } \\
(n=65)\end{array}$ & $\begin{array}{l}\text { Intravenous administration } \\
(n=51)\end{array}$ & $\begin{array}{l}\text { Subcutaneous administration } \\
(n=14)\end{array}$ & $p$-value \\
\hline \multicolumn{5}{|l|}{ Demographics } \\
\hline Sex (male) & 34 (52.3 \%) & 27 (52.9 \%) & $7(50.0 \%)$ & 1.000 \\
\hline Age (year-old) & $61.8(49.0-74.0)$ & $61.8(52.1-73.8)$ & $59.1(39.1-75.5)$ & 0.678 \\
\hline \multicolumn{5}{|l|}{ Comorbidities } \\
\hline Modified CCl & $3(1-5)$ & $3(2-5)$ & $1.5(0.3-5.8)$ & 0.478 \\
\hline $\mathrm{BMI}\left(\mathrm{kg} / \mathrm{m}^{2}\right)$ & $27.0(21.6-29.7)$ & $27.8(22.0-31.6)$ & $24.7(20.7-28.0)$ & 0.154 \\
\hline Obesity (BMI > 30) & 14 (22.2 \%) & $13(26.5 \%)$ & 1 (7.1\%) & 0.116 \\
\hline Diabetes & $8(12.3 \%)$ & $7(13.7 \%)$ & 1 (7.1\%) & 0.447 \\
\hline Immunosuppression & 11 (16.9\%) & 10 (19.6 \%) & 1 (7.1\%) & 0.253 \\
\hline Chronic renal failure & $9(14.8 \%)$ & $6(12.8 \%)$ & $3(21.4 \%)$ & 0.338 \\
\hline Chronic hepatic disease & 2 (3.3\%) & $2(4.3 \%)$ & $0(0 \%)$ & 0.591 \\
\hline Chronic pulmonary disease & 15 (24.6 \%) & 10 (21.3\%) & $5(35.7 \%)$ & 0.223 \\
\hline Congestive heart failure & 5 (8.1\%) & $3(6.3 \%)$ & $2(14.3 \%)$ & 0.314 \\
\hline Cerebrovascular disease & $4(6.6 \%)$ & $1(2.1 \%)$ & $3(21.4 \%)$ & 0.035 \\
\hline Peripheral artery disease & 5 (8.2 \%) & 4 (8.5 \%) & 1 (7.1\%) & 0.678 \\
\hline Neoplasic disease & $6(9.8 \%)$ & $6(12.8 \%)$ & $0(0 \%)$ & 0.193 \\
\hline Malignant hemopathy & $1(1.5 \%)$ & 1 (2.0\%) & $0(0 \%)$ & 0.785 \\
\hline Inflammatory systemic disease & $9(14.8 \%)$ & $9(19.1 \%)$ & $0(0 \%)$ & 0.079 \\
\hline Dementia & 2 (3.1\%) & $2(3.9 \%)$ & $0(0 \%)$ & 0.613 \\
\hline \multicolumn{5}{|l|}{ BJl types } \\
\hline Native BJ & $20(30.8 \%)$ & $16(31.4 \%)$ & $4(28.6 \%)$ & 0.559 \\
\hline Incl. arthritis & $5(25 \%)$ & $4(25.0 \%)$ & $1(25.0 \%)$ & 0.708 \\
\hline Incl. osteomyelitis & $5(25 \%)$ & $5(31.3 \%)$ & $0(0 \%)$ & 0.284 \\
\hline Incl. vertebral osteomyelitis & $10(50 \%)$ & $7(43.8 \%)$ & $3(75.0 \%)$ & 0.367 \\
\hline ODI & $45(69.2 \%)$ & $35(68.6 \%)$ & 10 (71.4\%) & 0.559 \\
\hline Incl. PJ| & $34(75.6 \%)$ & $28(80.0 \%)$ & $6(60.0 \%)$ & 0.187 \\
\hline Ind peripheral osteosynthesis & $8(17.8 \%)$ & $6(17.1 \%)$ & $2(20.0 \%)$ & 0.579 \\
\hline Incl. vertebral osteosynthesis & $3(6.7 \%)$ & $1(2.9 \%)$ & $2(20.0 \%)$ & 0.119 \\
\hline \multicolumn{5}{|l|}{ BJl characteristics } \\
\hline Evolution delay (weeks) & $1.6(0.1-6.7)$ & $1.6(0.4-9.2)$ & $0.9(0.2-3.1)$ & 0.299 \\
\hline Chronic BJI (> 3 weeks) & $23(35.4 \%)$ & 19 (37.3 \%) & $4(28.6 \%)$ & 0.754 \\
\hline \multicolumn{5}{|l|}{ Mechanism } \\
\hline Hematogenous & 30 (46.2 \%) & $24(47.1 \%)$ & $6(42.9 \%)$ & 1.000 \\
\hline Inoculation & $32(49.2 \%)$ & $25(49.0 \%)$ & $7(50.0 \%)$ & 1.000 \\
\hline Contiguity & $3(4.6 \%)$ & 2 (3.9\%) & $1(7.1 \%)$ & 0.523 \\
\hline MRSA & $11(16.9 \%)$ & $9(17.6 \%)$ & $2(14.3 \%)$ & 1.000 \\
\hline Plurimicrobial infection & 17 (26.2 \%) & $16(31.4 \%)$ & 1 (7.1\%) & 0.062 \\
\hline Biological inflammatory syndrom & $61(95.3 \%)$ & 47 (91.0 \%) & $14(100 \%)$ & 1.000 \\
\hline
\end{tabular}


Table 1 Description of the 65 included episodes of BJ and comparison between the intravenous and subcutaneous routes of administration (Continued)

\begin{tabular}{|c|c|c|c|c|}
\hline Maximal CRP value (mg/L) & $164(92-234.3)$ & $160.2(86.8-300.0)$ & $264.7(143.2-332.0)$ & 0.245 \\
\hline \multicolumn{5}{|l|}{ Local and general complications } \\
\hline Abscess & $26(40.0 \%)$ & $22(43.1 \%)$ & $4(28.6 \%)$ & 0.252 \\
\hline Sinus tract & $23(35.4 \%)$ & $21(41.2 \%)$ & $2(14.3 \%)$ & 0.056 \\
\hline Infective endocarditis & $2(3.7 \%)$ & $2(4.8 \%)$ & $0(0 \%)$ & 1.000 \\
\hline \multicolumn{5}{|l|}{ Hospitalization } \\
\hline Length of stay (weeks) & $5.6(1.9-8.9)$ & $5.8(2.3-8.9)$ & $3.8(1.6-8.1)$ & 0.580 \\
\hline Surgical management & $50(76.9 \%)$ & $38(74.5 \%)$ & $12(85.7 \%)$ & 0.491 \\
\hline Debridement (native BJ) & $8(40.0 \%)$ & $5(31.3 \%)$ & $3(75.0 \%)$ & 0.153 \\
\hline Conservative procedure ${ }^{a}$ & $24(53.3 \%)$ & $20(57.1 \%)$ & $4(40.0 \%)$ & 0.274 \\
\hline One-stage exchange ${ }^{a}$ & $3(6.7 \%)$ & $2(5.7 \%)$ & $1(10.0 \%)$ & 0.539 \\
\hline Two-stage exchange ${ }^{a}$ & $15(33.3 \%)$ & $11(31.4 \%)$ & $4(40.0 \%)$ & 0.440 \\
\hline \multicolumn{5}{|l|}{ Antimicrobial therapy } \\
\hline Total duration (weeks) & $26.8(17.7-42.8)$ & $26.2(17.9-41.6)$ & $28.4(17.8-48.4)$ & 0.406 \\
\hline Parenteral treatment & $64(98.5 \%)$ & $50(98.0 \%)$ & $14(100 \%)$ & 1.000 \\
\hline Duration (weeks) & $9.4(5.9-24.4)$ & $9.4(6.3-25.1)$ & $10.4(4.4-16.1)$ & 0.790 \\
\hline Combination therapy & $65(100 \%)$ & $51(100 \%)$ & $14(100 \%)$ & NC \\
\hline Duration (weeks) & $25.7(16.4-45.1)$ & $25.6(15.9-44.3)$ & $27.6(21.3-43.2)$ & 0.442 \\
\hline \multicolumn{5}{|l|}{ Teicoplanin use } \\
\hline IV route & $51(78.5 \%)$ & NA & NA & NA \\
\hline Loading dose & $55(85.9 \%)$ & $44588.0 \%)$ & $11(78.6 \%)$ & 0.521 \\
\hline Loading dose (mg/kg/12 h) & $5.7(4.7-6.5)$ & $5.6(4.7-6.5)$ & $6.0(5.4-6.7)$ & 0.218 \\
\hline Number of injections & $5(5-5)$ & $5(5-5)$ & $5(5-5)$ & \\
\hline Maintenance dose (mg/kg/24 h) & $5.7(4.7-6.5)$ & $5.6(4.7-6.5)$ & $5.9(5.1-6.8)$ & 0.406 \\
\hline Administration route switch & $7(10.8 \%)$ & $7(13.7 \%)$ & $0(0 \%)$ & 0.164 \\
\hline \multicolumn{5}{|l|}{ Duration of treatment } \\
\hline Total duration (weeks) & $6.0(2.7-9.9)$ & $6.0(2.9-9.7)$ & $5.8(3.0-11.6$ & 0.750 \\
\hline IV treatment duration (weeks) & $5.0(2.9-9.7)$ & $5.0(3.0-9.7)$ & NA & NA \\
\hline SC treatment duration (weeks) & $6.2(3.9-21.4)$ & NA & $5.3(2.8-11.6)$ & NA \\
\hline \multicolumn{5}{|l|}{ Pharmacological data } \\
\hline Number of dosages & $2.5(2-3.3)$ & $3(2-3)$ & $2(2-3.8)$ & 0.891 \\
\hline Initial $C_{\min }$ (day 3 to $5, \mathrm{mg} / \mathrm{L}$ ) & $11.7(9.2-16.3)$ & $10.8(8.6-15.2)$ & $13.8(11.4-16.2)$ & 0.130 \\
\hline Initial $C_{\min }>25 \mathrm{mg} / \mathrm{L}$ & $0(0 \%)$ & $0(0 \%)$ & $0(0 \%)$ & NC \\
\hline Initial $C_{\min }<15 \mathrm{mg} / \mathrm{L}$ & $36(73.5 \%)$ & $29(74.4 \%)$ & $7(70.0 \%)$ & 1.000 \\
\hline Overdose (day 1 to 14) & $10(15.6 \%)$ & $8(16.0 \%)$ & $2(14.3 \%)$ & 1.000 \\
\hline Delay for $C_{\min }>15$ mg/L (days) & $8.5(6-13)$ & $9(6-13)$ & $7(4.5-9.5)$ & 0.259 \\
\hline \multicolumn{5}{|l|}{ Companion drugs } \\
\hline Rifampicin & $16(24.6 \%)$ & $12(23.5 \%)$ & $4(28.6 \%)$ & 0.732 \\
\hline Fluoroquinolone & $29(44.6 \%)$ & $20(39.2 \%)$ & $9(64.3 \%)$ & 0.131 \\
\hline Pristinamycin & $11(16.9 \%)$ & $11(21.6 \%)$ & $0(0 \%)$ & 0.102 \\
\hline
\end{tabular}


Table 1 Description of the 65 included episodes of BJl and comparison between the intravenous and subcutaneous routes of administration (Continued)

\begin{tabular}{|c|c|c|c|c|}
\hline Teicoplanin-related AE & $6(10 \%)$ & $4(8.7 \%)$ & $2(14.3 \%)$ & 0.617 \\
\hline \multicolumn{5}{|l|}{ Follow-up and outcome } \\
\hline Follow-up period (weeks) & $91.1(50.6-182.6)$ & $98.0(58.3-194.9)$ & $68.2(40.7-100.3)$ & 0.112 \\
\hline One-month CRP level $<10 \mathrm{mg} / \mathrm{L}$ & 17 (27.9\%) & $14(28.0 \%)$ & $3(27.3 \%)$ & 1.000 \\
\hline Treatment failure & 27 (41.5\%) & $21(41.2 \%)$ & $6(42.9 \%)$ & 1.000 \\
\hline Persisting infection & $18(28.6 \%)$ & $14(28.0 \%)$ & $4(30.8 \%)$ & 1.000 \\
\hline Relapse & $6(9.7 \%)$ & $6(12.2 \%)$ & $0(0 \%)$ & 0.328 \\
\hline Iterative surgery & $23(35.9 \%)$ & 19 (38.0 \%) & $4(28.6 \%)$ & 0.754 \\
\hline BJl-related death & $1(1.6 \%)$ & $1(2.0 \%)$ & $0(0 \%)$ & 1.000 \\
\hline Superinfection & $13(20.0 \%)$ & $10(19.6 \%)$ & $3(21.4 \%)$ & 1.000 \\
\hline
\end{tabular}

$A E$ adverse event, $B J$ l bone and joint infection, $B M I$ body mass index, $C C l$ Charlson's comorbidity index, $C_{\text {min }}$ plasmatic teicoplanin trough concentration, $C R P C$ reactive protein, Incl Including, IV Intravenous, MRSA Methicillin-resistant Staphylococcus aureus, ODI orthopedic device-associated infection, $P J I$ prosthetic joint infection, SC subcutaneous

${ }^{a}$ for orthopedic device-related infections

\section{Discussion}

Although teicoplanin is among the drugs of choice for the treatment of staphylococcal BJI, efficacy, safety and pharmacokinetics data in that specific setting are scarce. Thus, the present study provides relevant features with regards to staphylococcal BJI management. Our study is subjected to limitations BJI studies generally encounter such as the retrospective design coupled to the inherent lack of control patients. The limited patients' recruitment, the variety of infection types, surgical management and medical treatment approaches also constitute a limitation to generalisation.

These current difficulties in the field of BJI explain the limited and controversial data available on the efficacy of teicoplanin in staphylococcal BJI. In past studies, treatment success rate ranged from 53 to $91 \%$ [11-14]. The low success rate observed in our study (60\%) may be explained by several factors. First, there is a significant selection bias as patients were recruited in a reference center dedicated to manage complex BJI with a high-risk of failure. In addition, most of past studies included native BJI with a relatively short follow-up $(<1$ year). Finally, pharmacodynamics parameters may impact the outcome $[15,16]$. In our study, a $C_{\min }$ reaching the therapeutic target of $15 \mathrm{mg} / \mathrm{L}$ was achieved in a quarter of cases at the first measurement (day 3 to 5) and in two thirds of patients within 2 weeks of treatment. The use of higher doses may improve these pharmacological parameters. In

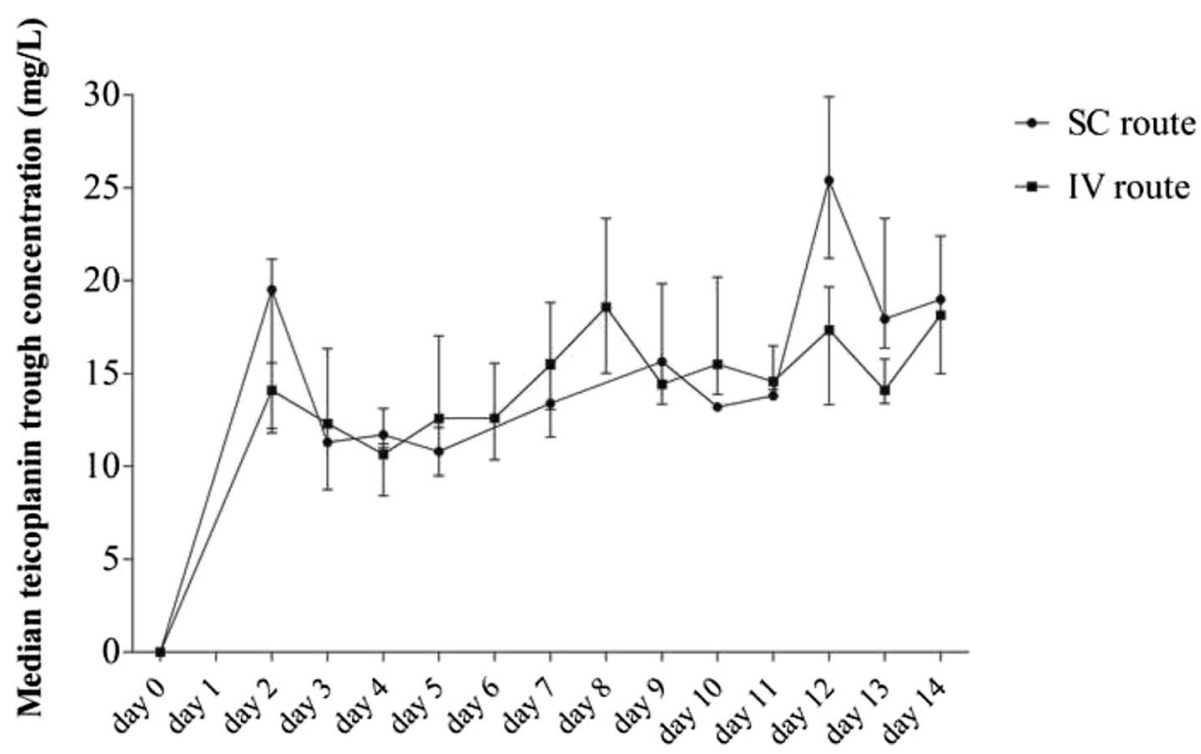

Fig. 1 Comparison of median teicoplanin trough concentrations in intravenously- and subcutaneously-treated patients during the first 2 weeks of treatment. Data are presented as median and interquartile ranges of teicoplanin trough levels available each day after treatment initiation 
Table 2 Description of the seven teicoplanin-related adverse events observed in 6 of the 60 included patients

\begin{tabular}{|c|c|c|c|c|c|c|c|c|c|c|c|}
\hline Case & $\begin{array}{l}\text { Modified } \\
\mathrm{CCl}\end{array}$ & BJl type & AE subtype & $\begin{array}{l}\text { CTCAE } \\
\text { grade }\end{array}$ & Route & Dosage & Delay & $\begin{array}{l}\text { Companion } \\
\text { drug }\end{array}$ & Stop & $\begin{array}{l}\text { Hospitalization } \\
\text { (duration) }\end{array}$ & Resolution \\
\hline 1 & 5 & $\begin{array}{l}\text { Acute } \\
\text { osteomyelitis }\end{array}$ & $\begin{array}{l}\text { Rash maculo- } \\
\text { papular }\end{array}$ & 2 & IV & $12 \mathrm{mg} / \mathrm{L}$ & 7 days & None & Yes & Yes (3 days) & Yes \\
\hline 2 & 4 & Acute PJI & $\begin{array}{l}\text { Rash maculo- } \\
\text { papular }\end{array}$ & 2 & IV & No & 10 days & $\begin{array}{l}\text { Oxacillin } \\
\text { Clindamycin }\end{array}$ & Yes & No (17 days) & Yes \\
\hline 3 & 0 & Acute VO & $\begin{array}{l}\text { Rash maculo- } \\
\text { papular } \\
\text { Pancytopenia }\end{array}$ & 3 & SC & No & 11 days & Rifampicin & Yes & No & Yes \\
\hline 4 & 5 & $\begin{array}{l}\text { Chronic } \\
\text { osteomyelitis }\end{array}$ & Headache & 1 & IV & $\begin{array}{l}27.8 \mathrm{mg} / \\
\mathrm{L}\end{array}$ & 20 days & Rifampicin & Yes & No & Yes \\
\hline 5 & 2 & Chronic VO & $\begin{array}{l}\text { Rash maculo- } \\
\text { papular }\end{array}$ & 3 & SC & No & 22 days & Ofloxacin & Yes & Yes (4 days) & Yes \\
\hline 6 & 2 & Acute VO & $\begin{array}{l}\text { Rash maculo- } \\
\text { papular }\end{array}$ & 2 & IV & No & 14 days & Ofloxacin & Yes & No & Yes \\
\hline
\end{tabular}

$A E$ adverse event, $B J$ l bone and joint infection, $C C I$ Charlson's comorbidity index, CTCAE common terminology criteria for adverse events, IV Intravenous, $P J I$ prosthetic joint infection, SC subcutaneous, VO vertebral osteomyelitis

the study by LeFrock et al, the teicoplanin $\mathrm{C}_{\min }$ averaged $10 \mathrm{mg} / \mathrm{L}$ after 6 days in patients receiving $6 \mathrm{mg} / \mathrm{kg} /$ day after 5 loading doses of $6 \mathrm{mg} / \mathrm{kg} / 12 \mathrm{~h}$ compared to $20 \mathrm{mg} /$ $\mathrm{L}$ from the third day in patients receiving $12 \mathrm{mg} / \mathrm{kg} /$ day after 5 loading doses of $12 \mathrm{mg} / \mathrm{kg} / 12 \mathrm{~h}$ [12]. If no difference was observed regarding osteomyelitis outcome, higher doses were associated with a better outcome among patients with native septic arthritis. Nevertheless, clinical outcome according to $C_{\min }$ was not an intended end-point in the study. Greenberg et al reported a favorable outcome in patients with a $C_{\min }>30 \mathrm{mg} / \mathrm{L}$, but with no comparative data [17]. It is our belief that the loading dose should be increased to $8 \mathrm{mg} / \mathrm{kg} / 12 \mathrm{~h}$ to optimize trough concentrations, particularly in case when orthopedic implant is retained. Other determinants of therapeutic success had already been described, such as inflammatory systemic disease, diabetes and abscess [18, 19]. Conversely, our study was not associated with MRSA as a negative prognostic factor as found elsewhere [20]. This last prognostic factor probably relies on the benefit of receiving anti-staphylococcal penicillins for a MSSA compared to glycopeptides [21, 22], which could not be highlighted in our series as all patients received teicoplanin, including those with MSSA infection. Finally, although all $S$. aureus isolates included in our study were tested susceptible to teicoplanin [23], the exact MIC of each isolate was not available and could consequently not be challenged as an outcome predictor. As described with vancomycin, high teicoplanin MICs (i.e., > $1.5 \mathrm{mg} / \mathrm{L}$ ) have been associated with unfavorable outcome and higher mortality rate among teicoplanin-treated MRSA bacteremia [24].

Regarding safety data, our results highlighted an excellent tolerance of teicoplanin with a $10 \%$ incidence of $\mathrm{AE}$, which is consistent with the toxicity rate of 9 to $18 \%$ observed in other similar studies [11, 13, 25].
However, the incidence of $\mathrm{AE}$ was probably been underestimated due to the retrospective nature of our study (memory bias for non-severe $\mathrm{AE}$ ). Indeed, in the prospective study of LeFrock et al, the rate of $\mathrm{AE}$ was $35 \%$, requiring discontinuation of treatment in $17 \%$ of the cases [12]. Very few data support enhanced AE related to teicoplanin dose increase [26]. LeFrock et al reported fever in 5.6 and $13.1 \%$ of patients receiving 6 and $12 \mathrm{mg} / \mathrm{kg} /$ day of teicoplanin, respectively, with similar data regarding cutaneous rashes (7.6 and $15.4 \%$, respectively) [12]. In our study, teicoplanin daily dose and overexposure within 2 weeks of treatment were not predictors of AE. In two other studies, a dose increase from 400 to $600 \mathrm{mg} /$ day was not associated with an increased risk of toxicity $[27,28]$.

The description of subcutaneous administration of teicoplanin is another important highlight of our study, showing similar efficacy, safety and pharmacokinetics characteristics compared to IV administration. The retrospective design may result in underestimating non-serious $\mathrm{AE}$ such as injection site reactions. In a recent prospective evaluation of SC teicoplanin in 30 patients, $90 \%$ of patients presented moderate local $\mathrm{AE}$ (grades 1-2) and no severe local reaction (grade $\geq 3$ ) [29]. Of note, none of our patients had SC teicoplanin infusion exceeding $600 \mathrm{mg}$, reported as an independent risk factor for local reaction in the study by El Samad et al [29]. Subcutaneous teicoplanin may be particularly useful in patients with BJI eligible for OPAT achieving efficacy and allowing cost reduction [30, 31]. Some authors have even proposed a 3-injections weekly regimen with a satisfactory success rate and an estimated saving of $\$ 60,000$ per episode of BJI [32, 33]. However, a study has tempered this suggestion by showing a non-significant trend toward a higher risk of failure in patients treated by teicoplanin for BJI [34]. Further studies, optimally with a prospective and controlled design, 
are warranted to assess both the risk-benefit as well as the cost-benefit of teicoplanin in staphylococcal BJI.

\section{Conclusion}

At the dose of $6 \mathrm{mg} / \mathrm{kg} / 24 \mathrm{~h}$ after a loading dose of $5 \mathrm{in}$ jections of $6 \mathrm{mg} / \mathrm{kg} / 12 \mathrm{~h}$, teicoplanin appeared as a welltolerated option in the treatment of S. aureus BJI, and may be recommended as an alternative to vancomycin in patients with MRSA infection or with intolerance to betalactam antibiotics. The use of higher doses must be discussed in order to optimize pharmacokinetic parameters of which clinical pertinence remains to be demonstrated. However, we believe that the loading dose should be increased to more rapidly reach the therapeutic target, which can be crucial for outcome of acute ODI with implant retention. Furthermore, subcutaneous administration of teicoplanin showed similar results in terms of efficacy, tolerance and pharmacokinetics compared to the intravenous administration, which encourage its use in OPAT. However, the implication of a multidisciplinary referral center for the management of complex BJI is needed to ensure a successful outpatient management, as suggested by the need for a close clinical, biological and pharmacological monitoring, particularly during the first 2 weeks of treatment when the majority of side effects occur.

\section{Additional files}

Additional file 1: Table S1. Comparison of patients presenting or not a teicoplanin overdose (teicoplanin plasmatic trough concentration > $25 \mathrm{mg} / \mathrm{L}$ ) and reaching or not the therapeutic concentration of $15 \mathrm{mg} / \mathrm{L}$ during the first 14 days of treatment (DOCX $19 \mathrm{~kb}$ )

Additional file 2: Table S2. Adverse events determinants in the 60 included patients treated by teicoplanin for a Staphylococcus aureus bone and joint infection (DOCX $22 \mathrm{~kb}$ )

Additional file 3: Table S3. Treatment failure determinants of the 65 included episodes of Staphylococcus aureus bone and joint infection (DOCX $25 \mathrm{~kb}$ )

\section{Abbreviations \\ 95\%Cl: $95 \%$ confidence interval; AE: Adverse event; BJl: Bone and joint infection; BMl: Body mass index; CCl: Charlson's comorbidity index; Cmin: Trough concentration; CNS: Coagulase negative Staphylococci; CRP: C- reactive protein; CTCAE: Common terminology criteria for adverse events; IQR: Interquartile range; IV: Intravenous; MRSA: Methicillin-resistant Staphylococcus aureus; MSSA: Methicillin-susceptible Staphylococcus aureus; ODI: Orthopaedic device-related infection; OPAT: Outpatient parenteral antimicrobial therapy; OR: Odd ratio; PJl: Prosthetic joint infection; SC: Subcutaneous; VO: Vertebral osteomyelitis}

\section{Acknowledgements}

Lyon Bone and Joint Infection Study Group: Coordinator: Tristan Ferry; Infectious Diseases Specialists - Tristan Ferry, Florent Valour, Thomas Perpoint, André Boibieux, François Biron, Patrick Miailhes, Florence Ader, Julien Saison, Sandrine Roux, Claire Philit, Fatiha Daoud, Johanna Lippman, Evelyne Braun, Christian Chidiac, Yves Gillet, Laure Hees; Surgeons - Sébastien Lustig, Philippe Neyret, Olivier Reynaud, Adrien Peltier, Olivier Cantin, Michel-Henry Fessy, Anthony Viste, Philippe Chaudier, Romain Desmarchelier, Thibault Vermersch, Sébastien Martres, Franck Trouillet, Cédric Barrey, Francesco Signorelli, Emmanuel
Jouanneau, Timothée Jacquesson, Ali Mojallal, Fabien Boucher, Hristo Shipkov, Mehdi Ismail, Joseph Chateau; Microbiologists - Frederic Laurent, François Vandenesch, Jean-Philippe Rasigade, Céline Dupieux; Nuclear Medicine Isabelle Morelec, Marc Janier, Francesco Giammarile; PK/PD specialists - Michel Tod, Marie-Claude Gagnieu, Sylvain Goutelle; Clinical Research Assistant Eugénie Mabrut

\section{Funding}

The study was founded by the Hospices Civils de Lyon and was carried out as part of our routine work. The funders had no role in study design, data collection and analysis, decision to publish, or preparation of the manuscript.

Availability of data and materials

All the data supporting the findings is contained within the manuscript.

\section{Authors' contributions}

OP participated in the design of the study, in the acquisition and interpretation of data, helped to statistical analysis and drafted the manuscript. TF participated in the design of the study and in the acquisition and interpretation of data. André Boibieux, EB, Anissa Bouaziz, JK, SL, FL, EF, FA and CC participated in the interpretation of data and helped to draft the manuscript. FV conceived of the study, participated in its design and coordination, helped to statistical analysis and to draft the manuscript. All authors read and approved the final manuscript.

\section{Competing interests}

The authors declare that they have no competing interests.

\section{Consent for publication}

Not applicable.

\section{Ethics approval and consent to participate}

This study received the approval of the French South-East ethics committee with the reference number CAL2011-021. In accordance with the French legislation, written informed patient consent was not required for any part of the study.

\section{Author details}

${ }^{1}$ Regional Referral Center for Bone and Joint Infection, Hospices Civils de Lyon, Lyon, France. ${ }^{2}$ Infectious Disease Department, Hospices Civils de Lyon, Groupement Hospitalier Nord, 103 Grande Rue de la Croix-Rousse, 69004 Lyon, France. ${ }^{3}$ Department of General Medicine, Claude Bernard Lyon 1 University, Lyon, France. ${ }^{4}$ INSERM U1111, International Center for Research in Infectiology (CIRI), Claude Bernard Lyon 1 University, Lyon, France.

${ }^{5}$ Department of Infectious Diseases, Lucien Hussel Hospital Center, Vienne, France. ${ }^{6}$ Department of Infectious Diseases, William Morey Hospital Center, Châlon-sur-Saône, France. ${ }^{7}$ Department of Infectious Diseases, Centre Hospitalier Métropole Savoie, Chambéry, France. 'ªboratory of Bacteriology, National Reference Center for Staphylococci, Groupement Hospitalier Nord, Hôpital de la Croix-Rousse, Hospices Civils de Lyon, Lyon, France. ${ }^{9}$ Department of Orthopedic Surgery, Groupement Hospitalier Nord, Hôpital de la Croix-Rousse, Hospices Civils de Lyon, Lyon, France.

Received: 14 May 2016 Accepted: 25 October 2016

Published online: 03 November 2016

\section{References}

1. Tong SYC, Davis JS, Eichenberger E, Holland TL, Fowler VG. Staphylococcus aureus infections: epidemiology, pathophysiology, clinical manifestations, and management. Clin Microbiol Rev. 2015;28:603-61.

2. Osmon DR, Berbari EF, Berendt AR, Lew D, Zimmerli W, Steckelberg JM, Rao $\mathrm{N}$, Hanssen A, Wilson WR. Diagnosis and management of prosthetic joint infection: clinical practice guidelines by the Infectious Diseases Society of America. Clin Infect Dis. 2013;56:e1-25.

3. Titécat M, Senneville E, Wallet F, Dezèque $H$, Migaud H, Courcol RJ, Loïez C. Microbiologic profile of Staphylococci isolated from osteoarticular infections: evolution over ten years. Surg Infect. 2015;16:77-83.

4. Valour F, Karsenty J, Bouaziz A, Ader F, Tod M, Lustig S, Laurent F, Ecochard R, Chidiac C, Ferry T. Antimicrobial-related severe adverse events during treatment of bone and joint infection due to methicillin-susceptible Staphylococcus aureus. Antimicrob Agents Chemother. 2014;58:746-55. 
5. Svetitsky S, Leibovici L, Paul M. Comparative efficacy and safety of vancomycin versus teicoplanin: systematic review and meta-analysis. Antimicrob Agents Chemother. 2009;53:4069-79.

6. Wood MJ. Comparative safety of teicoplanin and vancomycin. J Chemother. 2000;12 Suppl 5:21-5.

7. Landersdorfer CB, Bulitta JB, Kinzig M, Holzgrabe U, Sorgel F. Penetration of antibacterials into bone: pharmacokinetic, pharmacodynamic and bioanalytical considerations. Clin Pharmacokinet. 2009;48:89-124.

8. De Lalla F, Novelli A, Pellizzer G, Milocchi F, Viola R, Rigon A, Stecca C, Dal Pizzol V, Fallani S, Periti P. Regional and systemic prophylaxis with teicoplanin in monolateral and bilateral total knee replacement procedures: study of pharmacokinetics and tissue penetration. Antimicrob Agents Chemother. 1993:37:2693-8.

9. Lipsky BA, Berendt AR, Cornia PB, Pile JC, Peters EJ, Armstrong DG, Deery HG, Embil JM, Joseph WS, Karchmer AW, Pinzur MS, Senneville E. Infectious Diseases Society of America clinical practice guideline for the diagnosis and treatment of diabetic foot infections. Clin Infect Dis. 2012;2012(54):e132-73.

10. Charlson M, Szatrowski TP, Peterson J, Gold J. Validation of a combined comorbidity index. J Clin Epidemiol. 1994:47:1245-51.

11. Dacquet $\mathrm{V}$. Treatment of bone and joint infection with teicoplanin: a retrospective analysis of 50 cases. Int J Antimicrob Agents. 1996;7:49-51.

12. LeFrock J, Ristuccia A. Teicoplanin in the treatment of bone and joint infections: an open study. J Infect Chemother. 1999:5:32-9.

13. Marone P, Concia E, Andreoni M, Suter F, Cruciani M. Treatment of bone and soft tissue infections with teicoplanin. J Antimicrob Chemother. 1990;25:435-9.

14. Weinberg WG. Safety and efficacy of teicoplanin for bone and joint infections: results of a community-based trial. South Med J. 1993;86:891-7.

15. Harding I, MacGowan AP, White LO, Darley ES, Reed V. Teicoplanin therapy for Staphylococcus aureus septicaemia: relationship between pre-dose serum concentrations and outcome. J Antimicrob Chemother. 2000;45:835-41.

16. Wilson AP. Clinical pharmacokinetics of teicoplanin. Clin Pharmacokinet. 2000:39:167-83.

17. Greenberg RN. Treatment of bone, joint, and vascular-access-associated gram-positive bacterial infections with teicoplanin. Antimicrob Agents Chemother. 1990;34:2392-7.

18. Senneville E, Joulie D, Legout L, Valette M, Dezeque H, Beltrand E, Roselé B, d'Escrivan T, Loïez C, Caillaux M, Yazdanpanah Y, Maynou C, Migaud H. Outcome and predictors of treatment failure in total hip/knee prosthetic joint infections due to Staphylococcus aureus. Clin Infect Dis. 2011;53:334-40.

19. Marculescu CE, Berbari EF, Hanssen AD, Steckelberg JM, Harmsen SW, Mandrekar JN, Osmon DR. Outcome of prosthetic joint infections treated with debridement and retention of components. Clin Infect Dis. 2006;42:471-8.

20. Salgado CD, Dash S, Cantey JR, Marculescu CE. Higher risk of failure of methicillin-resistant Staphylococcus aureus prosthetic joint infections. Clin Orthop Relat Res. 2007:461:48-53.

21. Kim SH, Kim KH, Kim HB, Kim NJ, Kim EC, Oh MD, Choe KW. Outcome of vancomycin treatment in patients with methicillin-susceptible Staphylococcus aureus bacteremia. Antimicrob Agents Chemother. 2008;52:192-7.

22. Tice AD, Hoaglund PA, Shoultz DA. Risk factors and treatment outcomes in osteomyelitis. J Antimicrob Chemother. 2003;51:1261-8.

23. The European Committee on Antimicrobial Susceptibility Testing. Breakpoint tables for interpretation of MICs and zone diameters. Version 6.0. 2016.

24. Chang HJ, Hsu PC, Yang CC, Siu LK, Kuo AJ, Chia JH, Wu TL, Huang CT, Lee $\mathrm{MH}$. Influence of teicoplanin MICs on treatment outcomes among patients with teicoplanin-treated methicillin-resistant Staphylococcus aureus bacteraemia: a hospital-based retrospective study. J Antimicrob Chemother. 2012;67:736-41.

25. Pensotti C, Nacinovich F, Vidiella G, Carbone E, Marin M, Di Stéfano C, Stamboulian D. Teicoplanin in the treatment of bone and joint infections due to methicillin resistant staphylococci. Experience in adult patients. Medicina. 2002;62 Suppl 2:40-7.

26. Senneville E, Legout L, Corroyer B, Yazdanpanah Y, Mouton Y. Adequate use of teicoplanin in bone and joint infections. Med Mal Infect. 2004;34 Suppl 1:S99-102.

27. Matthews $P C$, Chue AL, Wyllie $D$, Barnett $A$, Isinkaye $T$, Jefferies $L$, Lovering A, Scarborough M. Increased teicoplanin doses are associated with improved serum levels but not drug toxicity. J Infect. 2014;68:43-9.

28. Matthews PC, Taylor A, Byren I, Atkins BL. Teicoplanin levels in bone and joint infections: are standard doses subtherapeutic? J Infect. 2007;55:408-13.

29. El Samad Y, Lanoix JP, Bennis Y, Diouf M, Saroufim C, Brunschweiler B, Rousseau F, Joseph C, Hamdad F, Ait Amer Meziane M, Routier S, Schmit JL.
Tolerability and plasma drug levels monitoring of prolonged subcutaneous teicoplanin treatment for bone and joint infections. Antimicrob Agents Chemother. 2016. (ahead of print).

30. Sims AL, Baker P, Bellamy R, McMurtry IA. Outpatient parenteral antibiotic therapy in primary hip and knee arthroplasty infection managed with debridement and retention of prosthesis: a retrospective cohort study. Surg Infect. 2013;14:293-6.

31. Nathwani D, Barlow GD, Ajdukiewicz K, Gray K, Morrison J, Clift B, France AJ, Davey P. Cost-minimization analysis and audit of antibiotic management of bone and joint infections with ambulatory teicoplanin, in-patient care or outpatient oral linezolid therapy. J Antimicrob Chemother. 2003:51:391-6.

32. Lazzarini L, Tramarin A, Bragagnolo L, Tositti G, Manfrin V, de LF. Three-times weekly teicoplanin in the outpatient treatment of acute methicillin-resistant staphylococcal osteomyelitis: a pilot study. J Chemother. 2002;14:71-5.

33. Graninger W, Wenisch C, Wiesinger E, Menschik M, Karimi J, Presterl E. Experience with outpatient intravenous teicoplanin therapy for chronic osteomyelitis. Eur J Clin Microbiol Infect Dis. 1995;14:643-7.

34. Mackintosh $\mathrm{CL}$, White $\mathrm{HA}$, Seaton RA. Outpatient parenteral antibiotic therapy (OPAT) for bone and joint infections: experience from a UK teaching hospital-based service. J Antimicrob Chemother. 2011;66:408-15.

\section{Submit your next manuscript to BioMed Central and we will help you at every step:}

- We accept pre-submission inquiries

- Our selector tool helps you to find the most relevant journal

- We provide round the clock customer support

- Convenient online submission

- Thorough peer review

- Inclusion in PubMed and all major indexing services

- Maximum visibility for your research

Submit your manuscript at www.biomedcentral.com/submit
Biomed Central 